\title{
Sol de sílica como agente ligante para concretos refratários
}

\author{
(Silica sol as a binder agent for refractory castables)
}

\author{
M. R. Ismael, F. T. Ramal Jr, V. C. Pandolfelli \\ Departamento de Engenharia de Materiais - DEMa \\ Universidade Federal de S. Carlos - UFSCar \\ Rod. Washington Luiz, Km 235, C.P. 676, S. Carlos, SP 13565-905 \\ marinaismael@polvo.ufscar.br,vicpando@power.ufscar.br
}

\begin{abstract}
Resumo
Grandes esforços têm sido empregados nas tentativas de substituição do cimento de aluminato de cálcio por outros tipos de agentes ligantes em concretos refratários. Adições superiores a 2-3\% em peso desse ligante podem ser prejudiciais ao comportamento de secagem e a refratariedade em sistemas contendo microssílica. A literatura sugere como interessante alternativa a substituição desse agente ligante pelo sol de sílica, que proporciona, entre outras vantagens, uma maior velocidade de secagem e sinterização do concreto. Neste trabalho, comparou-se o desempenho do cimento aluminoso e do sol de sílica como agentes ligantes para concretos refratários. Os concretos foram avaliados quanto ao comportamento de mistura, secagem, resistência mecânica, permeabilidade, explosão, porosidade e refratariedade sob carga, em diferentes temperaturas e tempos de cura. Os resultados indicaram que o uso do sol de sílica pode apresentar vantagens com relação ao cimento refratário, porém para sua correta utilização novas pesquisas serão necessárias.
\end{abstract}

Palavras-chave: concretos refratários, agente ligante, sol de sílica.

\begin{abstract}
Great efforts have been carried out in order to replace the calcium aluminate cement (CAC) by other types of binders in refractory castables. Contents higher than 2-3 wt\% of this binder can be deleterious to the drying behavior and to the system's refractoriness when microsilica is present. The literature relates as an interesting alternative the replacement of CAC for silica sol that provides, among another advantage, a higher drying speed and sinterability of the castable. In this work, the performance of CAC and silica sol as binder agents in refractory castables was compared. Their rheological and drying behavior, mechanical strength, permeability, explosion, porosity and refractoriness under load were evaluated. The results showed that the use of silica sol may be advantageous in comparison with the refractory cement, however in order to master the application of this binder, further research is needed.
\end{abstract}

Keywords: refractory castables, binder and silica sol.

\section{INTRODUÇÃO}

O grande interesse pela utilização de concretos refratários deve-se principalmente a sua facilidade de aplicação e a não necessidade de conformação e queima prévias. Além disso, a grande liberdade de projeto para geometrias mais complexas e o menor custo em relação aos pré-moldados tradicionais, tem aumentado expressivamente o interesse tecnológico nesse setor [1]. Um dos pontos ainda em desenvolvimento nesses sistemas é a necessidade de agentes ligantes com maior refratariedade e menor sensibilidade às condições de cura que os tradicionalmente empregados cimentos de aluminato de cálcio (CAC).

Para o sistema $\mathrm{Al}_{2} \mathrm{O}_{3}-\mathrm{CaO}-\mathrm{SiO}_{2}$, adições superiores a 2-3\% em peso de CAC podem induzir a formação de fases eutéticas de baixo ponto de fusão $\left(1200-1300{ }^{\circ} \mathrm{C}\right)$ [2]. Soma-se a isso, o fato de que com o uso do cimento aluminoso, valores de resistência mecânica a verde somente são alcançados, em geral, após um período de cura de 72 $\mathrm{h}$, o que prolonga sua etapa de processamento. Além disso, a secagem deve ser cuidadosamente projetada, devido à estrutura menos permeável que se obtém, para se evitar a geração de trincas e explosões [2]. Nesse contexto, a literatura [2] sugere como alternativa a substituição do cimento aluminoso pelo sol de sílica, que proporciona, entre outras vantagens, uma maior velocidade de secagem do concreto refratário, menores tempos de cura para atingir propriedades adequadas e elevada refratariedade.

O sol de sílica é uma dispersão coloidal de partículas sólidas de sílica em meio líquido. Quando usado em concretos refratários, a resistência mecânica é alcançada por meio da gelificação do sol de sílica, que ocorre quando os grupos silanol $(\mathrm{Si}-\mathrm{OH})$ presentes na superfície das partículas reagem entre si e se condensam. Essa reação resulta em 
uma ligação silano (-Si-O-Si-) que une duas partículas após contato e as torna hidrofóbicas. Novas partículas se unem a esse aglomerado e uma rede tridimensional é formada [3].

$\mathrm{O}$ sol de sílica pode apresentar uma série de vantagens em relação ao cimento aluminoso. Como não há ligações químicas com a água, ela pode ser eliminada rapidamente, reduzindo consideravelmente o tempo necessário para a realização da secagem. Por formar uma estrutura mais permeável, devido à ausência de fases hidratáveis, os riscos de explosões e trincamentos são menores. Adicionalmente, sua elevada pureza contribui para o aumento da refratariedade da maior parte dos sistemas aluminosos e sílico-aluminosos [2].

Este trabalho teve como objetivo comparar o desempenho de um concreto contendo cimento aluminoso e outro contendo sol de sílica como agente ligante, avaliando-os quanto ao comportamento de mistura, secagem, resistência mecânica, permeabilidade, explosão, porosidade e refratariedade sob carga, em diferentes temperaturas e tempos de cura.

\section{MATERIAIS E MÉTODOS}

\section{Formulação e mistura}

O estudo foi realizado utilizando-se concretos refratários aluminosos formulados segundo o modelo de empacotamento de partículas de Andreasen [4], com coeficiente (q) 0,21 e diâmetro máximo de partícula igual a $4750 \mu \mathrm{m}$ [5]. Com a mesma formulação do concreto contendo cimento aluminoso, para o concreto com sol de sílica substituiu-se a mesma quantidade em peso do agente ligante, mantendo inalterado os teores de matriz e agregado. As matériasprimas empregadas foram aluminas eletrofundidas brancas (Elfusa Geral de Eletrofusão Ltda) e calcinadas (A1000 SG e A17NE - Alcoa EUA), cimento de aluminato de cálcio (CA 14 - Alcoa EUA) e sol de sílica (Nalco). Ácido cítrico foi adicionado como dispersante na concentração de $0,36 \mathrm{mg} /$ $\mathrm{m}^{2}$, para ambos os concretos. No caso do sistema com sol de sílica, sínter de $\mathrm{MgO}\left(\mathrm{d}_{50}=15 \mu \mathrm{m} ; 98 \% \mathrm{MgO}\right)$ foi utilizado como acelerador da gelificação $(0,6 \%$ em peso da suspensão de sol de sílica) [2]. As características gerais do sol de sílica utilizado encontram-se na Tabela I.

Tabela I - Características gerais do sol de sílica. [Table I - Silica sol characteristics.]

\begin{tabular}{cc}
\hline \%peso $\mathrm{SiO}_{2}$ & $40 \%$ \\
\hline $\mathrm{pH}\left(25^{\circ} \mathrm{C}\right)$ & 10,1 \\
Tamanho de Partícula & $13 \mathrm{~nm}$ \\
Área Superficial & $230 \mathrm{~m}^{2} / \mathrm{g}$ \\
Viscosidade & $10 \mathrm{mPa} . \mathrm{s}$ \\
\hline
\end{tabular}

A mistura das matérias primas foi realizada em um reômetro para concretos [6]. Baseando-se na menor quantidade necessária de sol de sílica para os concretos atingirem adequada consolidação e potencializar as propriedades, o teor em peso de ligante adicionado foi de $3,5 \%$, tanto para as composições contendo sol de sílica quanto para as com CAC. O teor de água utilizado para o processamento foi de $5,2 \%$ em peso. Após a mistura, os diferentes sistemas foram moldados para a realização dos ensaios de secagem, resistência mecânica, permeabilidade, explosão, porosidade e refratariedade sob carga. As temperaturas de cura utilizadas neste trabalho foram de 8,30 e $50{ }^{\circ} \mathrm{C}$, durante $24,72,96$ e $168 \mathrm{~h}$. A cura foi realizada em ambiente saturado (umidade relativa $\cong 100 \%$ ) em câmara climatizada Vötsch 2020.

\section{Análise termogravimétrica}

Os ensaios de secagem foram realizados em corpos de prova cilíndricos $(\mathrm{h}=\mathrm{d}=40 \mathrm{~mm})$ úmidos (imediatamente após cura), em um equipamento que consiste de uma balança eletrônica (400 $\pm 0,002 \mathrm{~g})$ acoplada a um forno elétrico [7]. Foram coletadas simultaneamente a perda de massa da amostra e a temperatura do forno em função do tempo de ensaio. $\mathrm{O}$ aquecimento foi efetuado nas taxas de 5 e $20^{\circ} \mathrm{C} / \mathrm{min}\left(30-600^{\circ} \mathrm{C}\right)$, com patamar de $10 \mathrm{~min}$ a $600{ }^{\circ} \mathrm{C}$. A taxa de $20^{\circ} \mathrm{C} / \mathrm{min}$ foi utilizada considerando que quando o aquecimento é conduzido em taxas muito elevadas, a pressurização pode levar à explosão do material.

A perda de massa foi avaliada pelo parâmetro $\mathrm{W}$ e sua derivada em relação ao tempo (taxa de perda de massa), definidos respectivamente nas equações A e B:

$$
\begin{aligned}
& W(\%)=100 \times\left(\frac{M_{0}-M}{M_{0}-M_{f}}\right) \\
& \frac{d W}{d t}(\% / \min )=\left(\frac{\Delta W}{\Delta t}\right)
\end{aligned}
$$

W indica a perda de água que ocorre durante o aquecimento em relação a massa final de concreto seco; onde $\mathrm{M}$ é a massa instantânea medida no tempo $t_{i}, M_{o}$ a massa inicial e $M_{f}$ a massa final.

\section{Resistência mecânica}

O ensaio de resistência mecânica (compressão diametral - Norma ASTM C 496-90) foi realizado em amostras cilíndricas $(\mathrm{h}=\mathrm{d}=40 \mathrm{~mm})$ úmidas (imediatamente após cura), utilizando-se uma máquina de ensaios universal MTS 810 com taxa de aplicação de carga constante (42 N/s).

\section{Medidas de permeabilidade e porosidade}

Para a determinação da permeabilidade ao ar em temperatura ambiente, foram utilizados corpos de prova 
cilíndricos $(\mathrm{h}=25 \mathrm{~mm} ; \mathrm{d}=75 \mathrm{~mm})$ secos na mesma temperatura de cura durante $96 \mathrm{~h}$ em recipiente fechado contendo sílica gel. As constantes de permeabilidade Darciana $\left(\mathrm{k}_{1}\right)$ e não-Darciana $\left(\mathrm{k}_{2}\right)$ foram calculadas por meio do ajuste polinomial de pares de dados de pressão imposta e vazão resultante à equação de Forchheimer $(\mathrm{C})$, expressa para fluidos compressíveis como:

$$
\frac{P_{i}^{2}-P_{0}^{2}}{2 P L}=\frac{\mu V_{S}}{k_{1}}+\frac{\rho V_{S}^{2}}{k_{2}}
$$

onde $\mathrm{P}_{\mathrm{i}}$ e $\mathrm{P}_{\mathrm{o}}$ são, respectivamente, a pressão do ar na entrada e saída da amostra; $\mathrm{V}_{\mathrm{S}}$ é a velocidade do fluido; L é a espessura da amostra; $\mu$ é a viscosidade e $\rho$ a densidade do fluido na temperatura do ensaio (temperatura ambiente) [8].

A porosidade aparente dos concretos foi obtida pelo método de imersão (Arquimedes), utilizando querosene como líquido de imersão (norma ASTM C 20-87). O ensaio foi realizado para corpos de provas curados durante $168 \mathrm{~h} \mathrm{e}$ a seguir, secos em sílica gel por $72 \mathrm{~h}$ na mesma temperatura da cura e em amostras pré-queimadas a $1500{ }^{\circ} \mathrm{C}$ durante 24 h (taxa de aquecimento: $2{ }^{\circ} \mathrm{C} / \mathrm{min}$ ).

\section{Refratariedade sob carga}

Para a avaliação do comportamento de refratariedade sob carga (RUL) foram moldados corpos-de-prova cilíndricos $\left(50 \times 50 \mathrm{~mm}^{2}\right)$, contendo uma abertura central de $12,4 \mathrm{~mm}$. A análise foi realizada em amostras curadas durante 3 dias a $50{ }^{\circ} \mathrm{C}$ e pré-queimadas a $550{ }^{\circ} \mathrm{C}$ durante $12 \mathrm{~h}$ (taxa de aquecimento: $1{ }^{\circ} \mathrm{C} / \mathrm{min}$ ). $\mathrm{O}$ ensaio foi realizado a uma taxa de $5{ }^{\circ} \mathrm{C} / \mathrm{min}$ até a temperatura de $1500{ }^{\circ} \mathrm{C}$, sob carga compressiva de 0,2 MPa (NETZSCH - 421).

\section{RESULTADOS E DISCUSSÃO}

Na Fig. 1 é apresentado o comportamento de mistura para os concretos com diferentes sistemas ligantes.

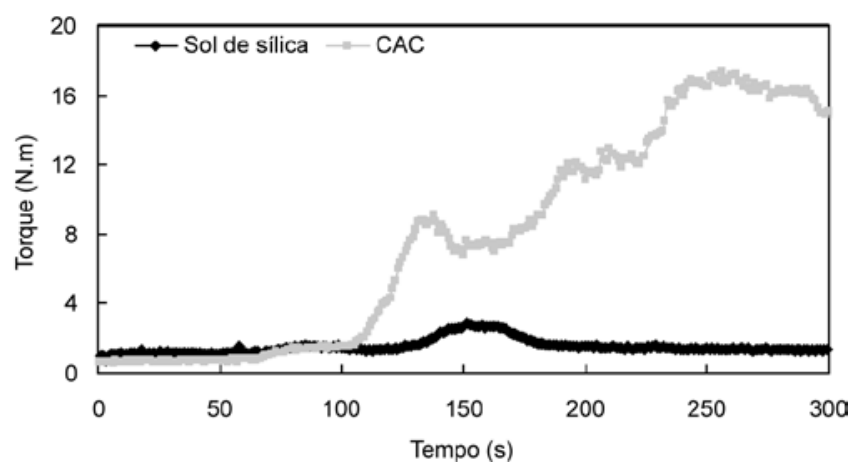

Figura 1: Comportamento de mistura para os concretos contendo diferentes agentes ligantes.

[Figure 1: Mixing behavior for castables prepared with different binders.]
Observam-se inferiores valores de torque para o concreto com sol de sílica, além de um menor tempo necessário para a completa mistura. Este fato pode ser associado a dois fatores principais: 1) o sol de sílica apresenta maior viscosidade que a água (Tabela I), o que mantém as partículas sólidas mais separadas, facilitando a mistura e 2) no sistema particulado o sol de sílica pode atuar como agente lubrificante, já que suas partículas são esféricas.

O perfil de secagem, variando-se tempo e temperatura de cura é ilustrado na Fig. 2, onde se pode avaliar o efeito da presença de água livre e das fases hidratadas nessa etapa do processo.

Em concretos refratários aluminosos, no primeiro estágio de aquecimento $\left(30-100{ }^{\circ} \mathrm{C}\right)$, a água presente em sua estrutura tende a deixar o interior do material e migrar para a superfície do corpo por evaporação. O segundo estágio da secagem (a partir de $100{ }^{\circ} \mathrm{C}$ ), é governado pela ebulição da água livre dentro da estrutura, sendo a formação de vapor intensificada com o aumento da temperatura. Com o final da ebulição, inicia-se o terceiro estágio, onde, quando presente, se verifica a decomposição de fases hidratadas [7].

Nota-se que, independente do tempo e da temperatura de cura utilizados, os concretos contendo sol de sílica apresentaram maior velocidade de secagem em relação aos com CAC. Isto pode estar relacionado ao fato de que na gelificação do sol uma estrutura mais permeável é gerada, permitindo a eliminação da água em temperaturas menores do que as observadas quando se utiliza o CAC como ligante. Além disso, concretos com sol de sílica não apresentaram o terceiro estágio de perda de massa, características dos concretos com CAC, o que representa uma importante informação tecnológica, uma vez que reduz as chances de danos durante o aquecimento. Para os concretos com sol de sílica, para as diferentes temperaturas de cura, o perfil de secagem não foi alterado com o aumento do tempo de cura (24-168 h), podendo-se assim afirmar que essas composições são pouco sensíveis a essa variável.

Comparando-se os resultados de resistência mecânica em função do tempo para diferentes temperaturas de cura (Fig. 3), nota-se um maior desenvolvimento da resistência mecânica para os concretos contendo CAC. Isto se deve a aceleração da hidratação do cimento com a temperatura, fato esse que contribui para o aumento da resistência mecânica [9].

Para os concretos com sol de sílica, a resistência mecânica permaneceu praticamente constante com o aumento do tempo de cura para as temperaturas de 8 e $30{ }^{\circ} \mathrm{C}$, indicando que o processo de gelificação do agente ligante foi pouco afetado por estas temperaturas. No entanto, na temperatura de cura de $50^{\circ} \mathrm{C}$, a gelificação foi desenvolvida e sua ocorrência pode estar associada ao fato de que o aumento de temperatura confere maior energia cinética às partículas, o que gera maiores probabilidades de colisões entre elas e, consequentemente, da formação da ligação silano (-Si-O-Si-).

As medidas de permeabilidade ao ar em temperatura ambiente (Fig. 4) comprovaram os elevados valores para 

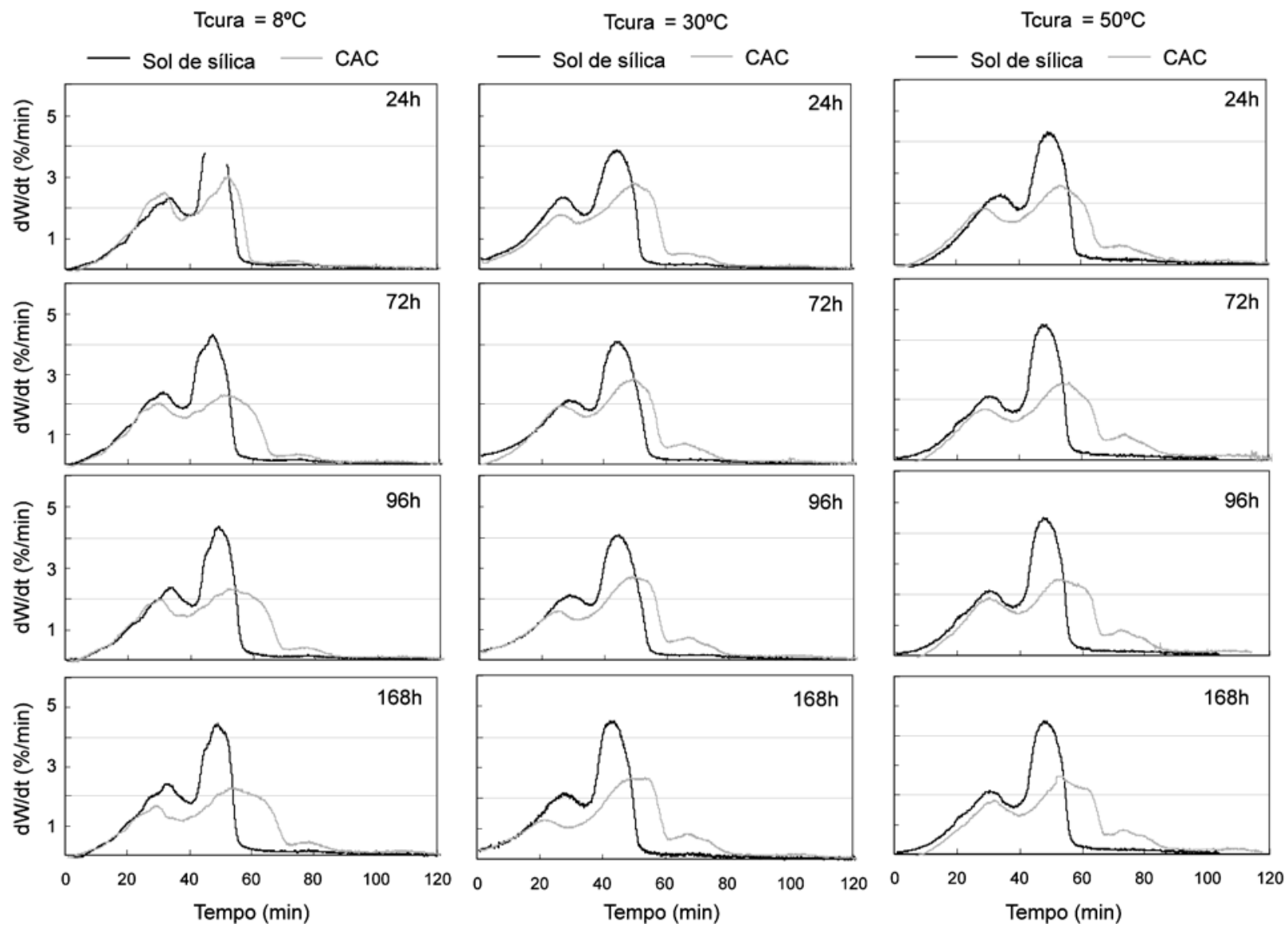

Figura 2: Taxa de perda de massa (dW/dt) em função do tempo de aquecimento para diferentes tempos e temperatura de cura para os concretos com diferentes sistemas ligantes.

[Figure 2: Drying rate (dW/dt) as a function of heating time for several curing conditions for castables prepared with different binders.]

o sistema com sol de sílica, provavelmente associados ao fato da gelificação deste ligante gerar uma estrutura mais aberta. Para todas as condições de cura apresentadas, podese afirmar que, devido a ordem de grandeza dos valores, a permeabilidade $\left(\mathrm{k}_{2}\right)$ dos concretos contendo sol de sílica permaneceu constante.

As medidas de permeabilidade dos concretos com CAC são coerentes com os trabalhos na literatura $[9,10]$. A formação de fases de baixa densidade, $\operatorname{como~}^{\mathrm{CAH}_{10}}(\mathrm{CaO}$. $\mathrm{Al}_{2} \mathrm{O}_{3} \cdot 10 \mathrm{H}_{2} \mathrm{O}$ ) e alumina gel em baixas temperaturas de cura $\left(8^{\circ} \mathrm{C}\right)$, aumenta com tempo de cura, bloqueando a passagem de ar através do concreto. O aumento da permeabilidade com a temperatura de cura facilitou a secagem (Fig. 2).

A porosidade aparente dos concretos comparados é ilustrada na Fig. 5.

Como um mesmo teor de água ( $\%$ em peso) foi adicionado para ambos os sistemas, isto implicaria, teoricamente, em valores de porosidade aparente similares. No entanto, devido ao seu tamanho nanométrico, as partículas de sol de sílica podem ter um comportamento semelhante à fase líquida. Como o aumento na quantidade de líquido causa o distanciamento entre as partículas da matriz e elevação da porosidade [11], a substituição direta do CAC por sol de sílica pode ter reduzido o empacotamento, gerando a superior porosidade.

A porosidade é uma importante variável microestrutural para obter-se bom desempenho dos concretos refratários. A resistência mecânica, a resistência à fluência e a resistência ao ataque por materiais corrosivos diminuem em função do aumento da porosidade. Portanto, a porosidade de concretos contendo sol de sílica ainda deve ser ajustada para que propriedades apropriadas às condições de serviço sejam obtidas.

Os resultados do teste de explosão (Tabela II) confirmam que a elevada permeabilidade dos concretos com sol de sílica reduziu os riscos de pressurização.

Para os concretos com sol de sílica, não foi verificada explosão independente do tempo e temperatura de cura, o que pode ser atribuído à presença de canais permeáveis, que facilitam o escoamento do vapor pressurizado. No caso do material com cimento refratário (CAC), na temperatura de $8{ }^{\circ} \mathrm{C}$ (Tabela II), as amostras curadas durante $24 \mathrm{~h}$ não 

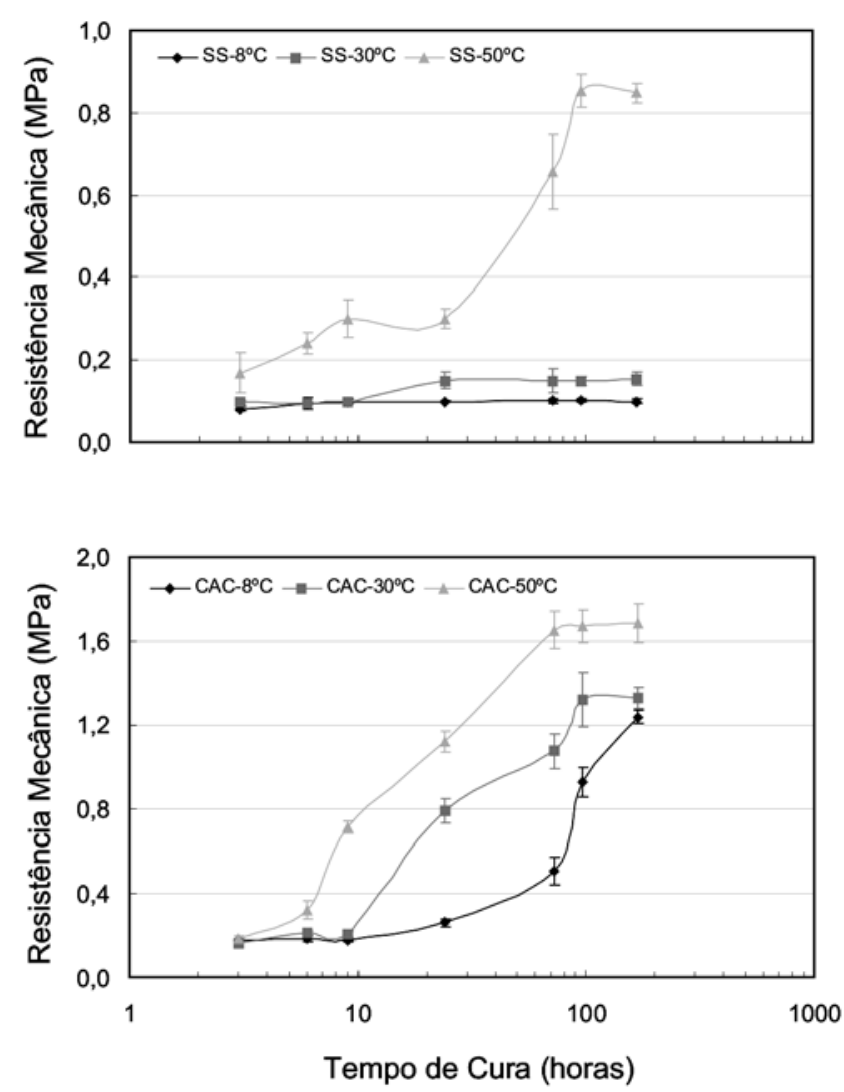

Figura 3: Resistência mecânica em função do tempo de cura para diferentes temperaturas para os sistemas com diferentes agentes ligantes.

[Figure 3: Mechanical strength as a function of curing time and temperatures for castables prepared with different binders.]

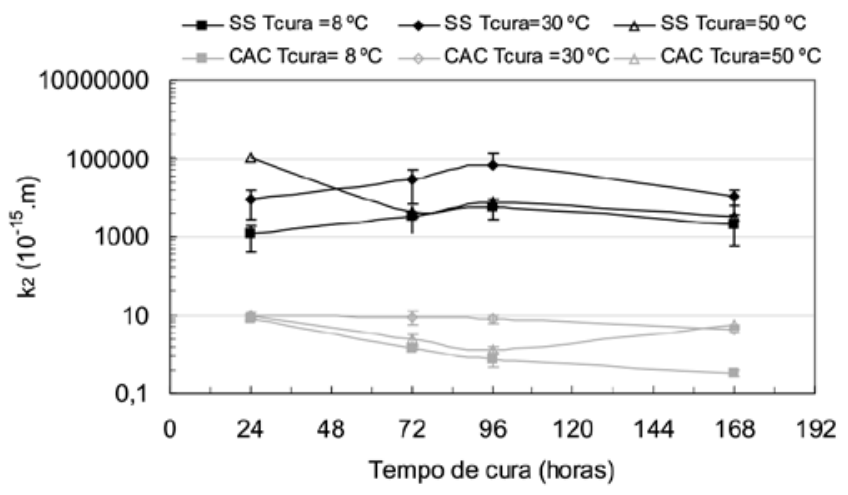

Figura 4: Permeabilidade $\left(\mathrm{k}_{2}\right)$ em função do tempo de cura para diferentes temperaturas para os concretos contendo cimento de aluminato de cálcio (CAC) e sol de sílica (SS).

[Figure 4: Permeability measurements ( $k_{2}$ ) as a function of curing time for different temperatures for castables with calcium aluminate cement (CAC) and silica sol (SS).]

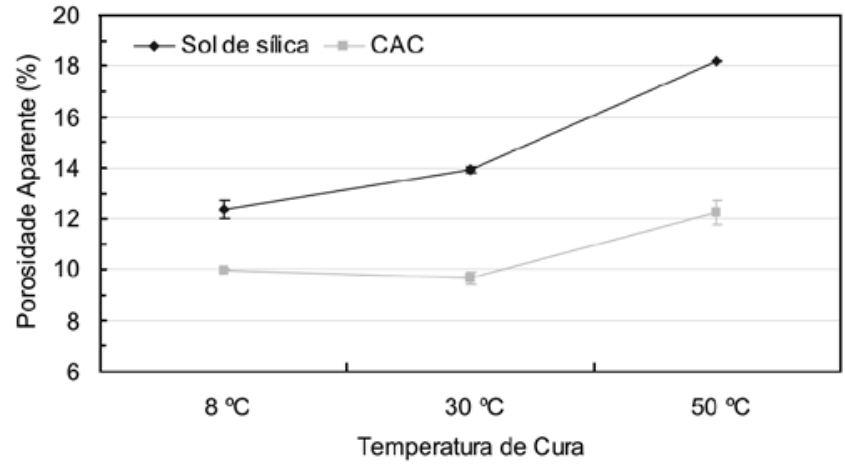

Figura 5: Porosidade aparente em função da temperatura de cura para os concretos produzidos com diferentes agentes ligantes.

[Figure 5: Apparent porosity (\%) as a function of curing temperature for castables with different binders.]

Tabela II - Tempo (t) e temperatura de explosão (T) em função do tempo de cura para os concretos com sol de sílica (SS) e com cimento de aluminato de cálcio (CAC), curados a $8^{\circ} \mathrm{C}$.

[Table II - Explosion time ( $t$ ) and temperature (T) according to curing time for castables with silica sol (SS) and with calcium aluminate cement $(C A C)$, cured at $8{ }^{\circ} \mathrm{C}$.]

\begin{tabular}{|c|c|c|c|c|}
\hline \multirow{2}{*}{$\begin{array}{l}\text { Tempo de } \\
\text { Cura (h) }\end{array}$} & \multicolumn{2}{|r|}{ SS } & \multicolumn{2}{|c|}{ CAC } \\
\hline & $\mathrm{t}(\min )$ & $\mathrm{T}\left({ }^{\circ} \mathrm{C}\right)$ & $\mathrm{t}(\min )$ & $\mathrm{T}\left({ }^{\circ} \mathrm{C}\right)$ \\
\hline 24 & $\begin{array}{c}\text { não } \\
\text { explodiu }\end{array}$ & $\begin{array}{c}\text { não } \\
\text { explodiu }\end{array}$ & $\begin{array}{c}\text { não } \\
\text { explodiu }\end{array}$ & $\begin{array}{c}\text { não } \\
\text { explodiu }\end{array}$ \\
\hline 72 & não & não & & \\
\hline 96 & $\begin{array}{l}\text { explodiu } \\
\text { não }\end{array}$ & $\begin{array}{l}\text { explodiu } \\
\text { não }\end{array}$ & 23 & 414 \\
\hline 168 & $\begin{array}{l}\text { explodiu } \\
\text { não }\end{array}$ & $\begin{array}{l}\text { explodiu } \\
\text { não }\end{array}$ & 25 & 447 \\
\hline & explodiu & explodiu & 27 & 550 \\
\hline
\end{tabular}

explodiram, uma vez que nessa condição, a fase hidratada predominante $\left(\mathrm{CAH}_{10}\right)$ ainda não se desenvolveu o suficiente para reduzir a permeabilidade [10]. Com tempos de cura maiores (72 a $168 \mathrm{~h}$ ), foi verificado um aumento no tempo e temperatura de explosão, devido a superior resistência mecânica do concreto (Fig. 3).

Para as temperaturas de cura de 30 e $50{ }^{\circ} \mathrm{C}$, nenhum dos concretos contendo CAC explodiu. Tal comportamento pode ser explicado por meio de um balanço entre a resistência mecânica e a permeabilidade [12]. A partir do momento que a formação de vapor supera a sua taxa de liberação, a pressão no interior do corpo cerâmico se eleva, causando a explosão. Por outro lado, o aumento de resistência mecânica contribui para o aumento da resistência à explosão, uma vez que o corpo cerâmico pode suportar um maior nível de pressurização.

O comportamento termo-mecânico dos sistemas refratários foi analisado através do ensaio de refratariedade 
sob carga, apresentado na Fig. 6.

Devido a elevada área superficial do sol de sílica (Tabela I), verifica-se uma maior sinterabilidade para o sistema contendo este ligante. Quanto maior a reatividade do sistema, maior a velocidade de sinterização e, consequentemente, a deformação sob carga [13].

A expansão detectada próximo a $1500{ }^{\circ} \mathrm{C}$ para ambas composições, deve-se provavelmente, a formação das fases mulita e $\mathrm{CaO} .6 \mathrm{Al}_{2} \mathrm{O}_{3}\left(\mathrm{CA}_{6}\right)$ para os concretos com sol de sílica e cimento de aluminato de cálcio, respectivamente. A proporção de alumina e sílica, além da elevada área superficial do sistema, favoreceriam a geração da fase mulita, que confere maior resistência mecânica a quente e ao choque térmico em concretos refratários. A formação da fase expansiva $\mathrm{CA}_{6}$ gera maior porosidade no sistema (Tabela III) além de diminuir a resistência ao choque térmico [14].

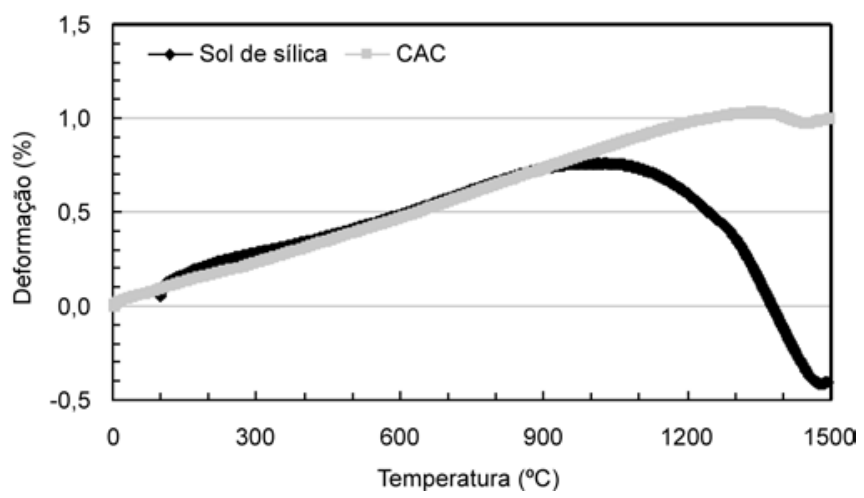

Figura 6: Refratariedade sob carga para concretos com diferentes agentes ligantes.

[Figure 6: Refractoriness Under Load for castables with different binders.]

Tabela III - Porosidade aparente (PA) para sistemas com sol de sílica (SS) e cimento aluminoso (CAC), para corpos de provas pré-queimados a $1500{ }^{\circ} \mathrm{C}$.

[Table III - Apparent porosity (PA) for castables containing silica sol (SS) and calcium aluminate cement (CAC), for samples pre-fired at $1500{ }^{\circ} \mathrm{C}$.]

\begin{tabular}{cc}
\hline Agente Ligante & PA (\%) \\
\hline SS & $15,5 \pm 0,2$ \\
CAC & $19,9 \pm 0,2$ \\
\hline
\end{tabular}

\section{CONCLUSÕES}

Comparando-se ambos os sistemas analisados, nota-se que o sol de sílica como agente ligante pode apresentar vantagens em relação aos concretos contendo cimento de aluminato de cálcio.
A facilidade de mistura e secagem, a elevada permeabilidade e a baixa susceptibilidade às condições de cura do sistema ligado com sol de sílica, permitiram uma redução no tempo total de processamento do concreto. A elevada área superficial do sol de sílica gerou uma maior reatividade do sistema, favorecendo a sinterização.

É razoável supor que superiores valores de resistência mecânica a verde possam ser obtidos, i) adequando-se a distribuição granulométrica do material, o que resultaria em menor porosidade, e ii) realizando-se a cura em ambiente seco, uma vez que sistemas com sol de sílica não necessitam de água para atingirem a gelificação.

\section{AGRADECIMENTOS}

Os autores agradecem a CAPES, a FAPESP, a Alcoa Alumínio S.A., a Elfusa Geral de Eletrofusão Ltda e a Magnesita S.A. pelo apoio na execução deste trabalho; e ao Dr. Sérgio F. dos Santos e Dr. Rafael Salomão pelas suas colaborações.

\section{REFERÊNCIAS}

[1] W. E. Lee, W. Vieira, S. Zhang, K. G. Ahari, H. Sarpoolaky, C. Parr, Int. Mater. Rev. 46, 3 (2001) 145.

[2] S. Banerjee, Am. Ceram. Soc. Bull. 77, 10 (1988) 59.

[3] R. K. Iler, "The chemistry of silica: solubility, polymerization, colloid and surface properties, and biochemistry", John Wiley \& Sons, New York, (1979) 312.

[4] I. R. Oliveira, A. R. Studart, R. G. Pileggi, V C. Pandolfelli, "Dispersão e empacotamento de partículas - princípios e aplicações em processamento cerâmico", Fazendo Arte Editorial, S. Paulo, Brasil (2000) 119.

[5] R. G. Pileggi, F. Ortega, R. Morabito, S. L. Vendrasco, V. C. Pandolfelli, Cerâmica 44, 289 (1998) 189.

[6] R.G. Pileggi, V.C. Pandolfelli, A.E. Paiva, J. Gallo, Am. Ceram. Soc. Bull. 79, 1 (2000) 54-58.

[7] M. D. M. Innocentini, F. A. Cardoso, M. M. Akyioshi, V. C. Pandolfelli, J. Am. Ceram. Soc. 86, 7 (2003) 1146.

[8] M. D. M. Innocentini, A. R. F. Pardo, V. R. Salvini, V. C Pandolfelli, J. Am. Ceram. Soc. 78, 11 (1999), 64.

[9] F. A. Cardoso, M. D. M. Innocentini, M. M. Akiyoshi, V. C. Pandolfelli, Refrac. Appl. News 9, 2 (2004), 12.

[10] F. A. Cardoso, M. D. M. Innocentini, M. M. Akiyoshi, V. C. Pandolfelli, J. Am. Ceram. Soc. 24 (2004) 2073.

[11] F. T. Ramal Jr, R. Salomão, V. C.Pandolfelli, Cerâmica 50, 315 (2004) 197.

[12] R. D. dos Anjos, M. R. Ismael, F. T. Ramal Jr, V. C. Pandolfelli, Cerâmica 50, 316 (2004) 331.

[13] J. S. Reed, "Principles of ceramics processing", $2^{\text {nd }} E d$., John Wiley \& Sons, New York (1995) 583.

[14] C. Domínguez, J. Chevalier, R. Torrecillas, L. Gremillard, G. Fantozzi, J. Eur. Ceram. Soc. 21 (2001) 907-917.

(Rec. 21/06/2005, Ac. 25/11/2005) 